\title{
张氏兄弟在日里地区建设中参与的角色
}

\section{PERAN SERTA TJONG BERSAUDARA DALAM PEMBANGUNAN TANAH DELI}

\author{
Rudiansyah ${ }^{1}$; Arthur S. Nalan ${ }^{2}$; Yang Jing ${ }^{3}$
}

Faculty of Humanities University of Sumatera Utara

Emai1:rudiansyah@usu.ac.id; arthur@isbi.ac.id; 0193701183@shisu.edu.cn

\section{摘要}

日里地区最初是从 1860 年代开始被来自中国的种植者和贸易商的活动所 逐渐开发建设的。在日里河东侧的开阔田野周围的区域是当时日里地区早期的中 心。在开发日里地区之后, 凯萨万地区紧随其后, 成为了华人社区居住区以及满 足社区需要的商品和商店供应场所的集中地, 尤其是为种植园的活动所需。来自 中国的移民在作为少数种族的 “中间人” 角色这一方面具有重要地位, 更在日里 地区的建设和发展中发挥了重要作用。这项研究的标题是 “张氏兄弟在日里地区 建设中参与的角色”, 并利用了昆托维约的历史解释法。本文的内容阐述了来自 中国广东梅县的张榕轩和张阿辉移民到日里地区, 与日里苏丹国和荷兰东印度政 府共同建设种植园的商事活动。不仅如此, 张氏兄弟也为日里地区或今日的棉兰 市的发展做出了巨大的贡献, 包括他们建造的礼拜场所、学校、银行、铁路运输 设施、桥梁、市场和医院。

关键词: 历史解释法; 角色参与; 张榕轩; 张阿辉; 日里地区

\section{一 引言}

\section{1 前言}

华人开始往印尼移民, 尤其是日里地区 (棉兰市), 发生于 12 世纪初。 他们还向当地人民介绍自己的宗教, 艺术和文化。随着几十个 烟草种植园的 建立, 华人向东苏门答腊岛迁移的浪潮持续增长。1 863 年第一次有需要烟草 种植园, 然后在 20 年内达到数十个时, 种植业主开始修建道路, 桥 梁, 电话, 电报, 银行, 酒店和其他公共设施, 以支持种植园的运营。这个相对容易建立的 种植园是由于马来苏丹国（日里、亚沙汉、昔利冷和冷吉）向欧洲的商人提供 了广阔的土地（特许经营权）。因为这片土地被认为是苏 丹国（日里）的财产， 
所以这些殖民地私人投资者向苏丹国租借土地 (Rudiansyah, 2016, 32)。

随着开始派来来自中国的劳动力, 东苏门答腊正在组建一个殖民地经济 增长区。1863 年, 基础设施和其他社会设施的建设开始实施。这种基础设施 的建设需要许多方面的参与, 特别是荷兰私人投资者主宰的殖民地投资者。这 些殖民地私人投资者参与建立棉兰并将其建设成为一个殖民城市, 该城市旨 在向当时的国际资本主义中心提供经济利益。在日里（棉兰）土地 开发中，需 要具备设计技能的资本和经济行为者。日里地区成为一个现代殖民城市, 在来 到东苏门答腊的中国移民潮中, 有一位华裔社区领导人张榕轩 和张阿辉出生在 广东松口，中国南部（Rudiansyah，2017：45)。

1877年，在 22 岁的时候，殖民地政府指张榕轩为翁鲁斯特岛（Onrust）的 华裔社区领导，在巴达维亚海岸前。然后在 1880 年张榕轩离开翁鲁斯特 岛到 日里港口。张榕轩担任日里地区 (棉兰) 的官员和华人的官方代表。1884年, 张榕轩成为中华民族在棉兰的中尉; 1893 年担任队长并于 1898 年 担任东苏门答 腊省华人的荷兰印度政府的最高代表。被指定为最高代表后，荷兰东印度政府 要求张榕轩确定税率并处理当地的税收问题。

凭张榕轩地位和信任, 不让他粗心与器张, 他的慷慨大方总是成为了张 榕轩的特点, 甚至他也成为了日里地区发展的投资者。作为著名的经济人士和 城市建设者, 张榕轩可以更容易地与各种社会背景相结合。在建立社会 友谊时, 张榕轩与殖民地政府和苏丹及其富有家人有较好关系。殖民地政府 要求张榕轩 作为采购与种植园和建设城市相关物品的中介。

在三十三年（1867-1900）期间, 张榕轩不仅在日里地区，而且在槟城和 中国建立了他的商业帝国。凭借这一职位, 张榕轩可以找到其业务扩展的 战略 位置, 例如在殖民地政府中建立水果市场和肉类市场。

张榕轩死于 1911 年, 当时他还在人生的顶峰, 这导致张榕轩持有的商业帝 国由张阿辉继续管理, 取代作为华裔社会领导者的角色。张阿辉在日里 地区发 展中的作用就是一个榜样, 显示出一个非常突出的领导特征。他他经常 在华人 与其他人发生争执的情况下进行调解。在种植区, 劳动者与荷兰公司 之间经常 
发生冲突, 并导致混乱。由于他的能力, 荷兰人要求张阿辉帮助克 服各种问题。 由于取得了辉煌的成就, 在 1911 年, 张阿辉被任命为华人甲 必丹 (Majoor der Chineezen) 引领日里地区的华裔社会。华人甲必丹 (Majoor der Chineezen) 是由荷兰应特定的民族或社区领袖的术语, 而这个级别从中尉或市长的助理开 始, 然后继续到市长的主要位置, 当时是最高和久负盛名的位置 (Buiskoo1, 2009:2)。

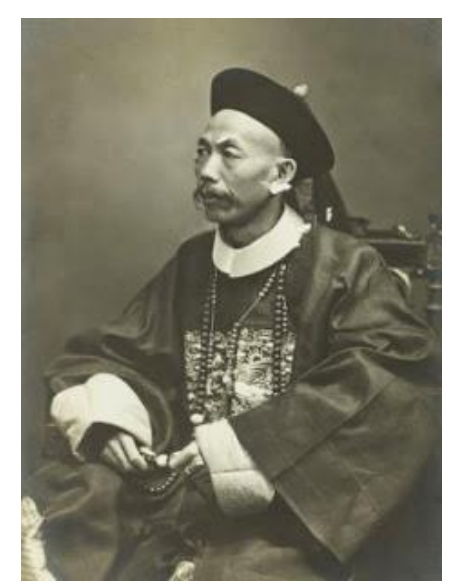

图 1 张耀轩 (Dok. Arsip Tjong Yong Hian Gallery)

在日里地区, 张耀轩 (即张阿辉) 拥有广泛的社会关系, 并以一慷慨而 仁慈的交易员而闻名, 之后他与 Makmoen Al Rasjid Perkasa Alamsyah 和 Tuanku Raja Moeda 的日里苏丹保持良好关系。在高度忠诚的情况下, 张耀轩 成功 地成为了日里苏丹可靠的人, 并开始处理一些商业事务。因此, 他在日里 地 区赢得了良好的声誉和知名度。他在商人和政府官员中都很出名。与日历苏 丹的良好关系成为了张耀轩开展业务成功的开始。日里苏丹允许张耀轩出于 日 里地区烟草种植的目的。

张耀轩受到尊重, 此外他还主宰了经济和政治领域。其商业帝国包括房 地产, 酒店, 银行, 种植园, 棕榈油和糖厂。张耀轩在担市长期间, 还在 日里 地区开展了自己的业务。张耀轩所发展的一项业务是建立了凯萨张耀轩所发展 的一项业务是建立了凯萨文银行, 作为日里地区货币储存的先驱。教育设施, 
医院，礼拜场所和其他公共设施 的发展使得张耀轩成为日里地区的杰出人物。

以上的设施之所以受到支持, 是因为张耀轩与当时成为马来社会领袖的日里苏 丹国具有紧密关系。

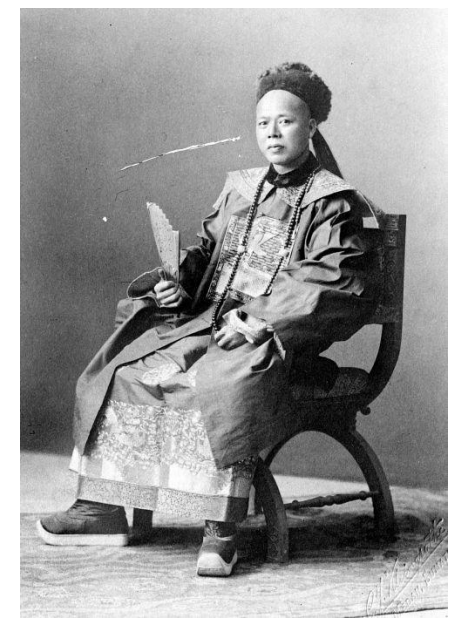

图 2 张阿辉 (Dok. Arsip Museum Tjong A Fie Mansion)

\section{2 研究对象}

本文以帮助建设日里地区的其祖先来自广东墨现的中国人为研究对象, 进行 实地观察。

\section{3 研究方法}

文献综述: 检索、整理和研究中国和印尼研究的相关文献, 论文、期刊、书 籍等中国社会人士的作用和贡献, 并运用相关研究成果作为本研究的支持理论和 参考方法。

定性方法: 本研究采用定性方法, 也就是描述性探讨的定性方法。该方法被 认为可根据实地观察和分析结果生成相关数据。

理论: 本文运用印尼历史学家昆托沃约托的历史解释理论, 一位也可被称为文学 家的历史学家。历史作为一门科学, 下面将阐述历史解释这一概念: 鉴于该学科 的类型, 请时刻秉持一下三点内容:（1）历史解释是一种解释学, 其实是 “领悟” 和 “解释” 两方面; (2) 历史解释是一种时间跨度极长的解释; (3) 历史解释 是针对单个事件的解释 (昆托沃约托, 2008：10）. 本文将解读和阐释日里地区 与张氏兄弟的关系, 张氏兄弟在日里地区的社会交往以及文化联系方面的时间跨 度, 以及关于张氏兄弟在日里地区开发中的作用和角色的单一事件, 直到得出明 
确的特征和结论。

\section{二 文献综述}

\section{1 印尼华人的相关研究}

\subsection{1 日里地区华人群体的到来}

向东苏门答腊的华人移民浪潮随着数十个大型烟草种植园的建立愈演愈烈。 当烟草种植园第一次在 1863 年被建立的时候，仅仅短短二十年的时间，其数量 便激增至数十个。种植园主开始造桥, 修路, 建设电话线、电报, 设立银行、酒 店以及其它的公共设施来支持他们种植园的运作。种植园建设的相对容易源自于 马来苏丹 (日里、Asahan, Serdang, langakt) 的对欧洲荷兰私人企业家给予土 地这一政策。

随着开始从中国引进劳动力，东苏门答腊地区正被规划成一个殖民地的经 济增长区。自 1863 年以来, 该地开始进行基础设施和其他社会设施的建设。建 造这一基础设施需要许多当事方的参与, 特别是当时由荷兰私人金融家主导的殖 民金融家。正是这些殖民地的私人金融家将棉兰建成一个殖民城市，他们的目的 旨在将经济利润提取到国际资本主义的中心。在日里土地开发中, 需要资本和经 济行为者具备将日里设计成现代殖民城市的技能。在中国向东苏门答腊移民的浪 潮中, 有一个叫张榕轩的人, 他在中国广东梅县出生于 1850 年。在巴达维亚 (雅 加达）经营了几年后, 张榕轩于 1870 年来到日里寻求财富。1 870 年是殖民私 人资本流入印尼群岛的一年, 包括东苏门答腊地区。人们并不了解张榕轩是如何 构建他的交易活动, 并管理他的商业帝国, 直到他生命的尽头。众所周知, 在他 来到日里近十年后, 他的商业活动规模持续增长, 并在相对较短的时间里成为当 时伟大的商人之一。这种成功从它拥有越来越多的公司中可见一斑。张榕轩经营 活动的发展与种植园活动的存在有关。种植园成为经济活动的一种飞速增长的力 量, 并给张榕轩带来了巨大的利益。

在拓展了日里的业务后, 张榕轩于 1879 年邀请他的弟弟张阿辉到日里管 理一家合资企业。张阿辉的到来进一步使得张榕轩的商业帝国崛起。除源自欧洲 荷兰的资本家之外, 张氏兄弟也同样为日里的现代化开发奠定了基础。张榕轩将 曾经的乡村风格的日里改造成一座现代化的殖民城市。在建设作为殖民地卫星城 
的日里的基础设施的同时, 张榕轩并不孤单。他、荷兰政府和殖民地资本的所有 者共同建造了日里这片土地。殖民政府本身需要注入的资本来发展城市。

\subsection{2 张榕轩}

Rebecca Chandra（2011 年), 在她的书”张榕轩：一个真正的领袖的遗产” 中, 作者讲述了棉兰市的传奇人物, 张榕轩和张阿辉的传奇的人生历程。本书的 内容是他们最初作为一个一穷二白的年轻人如何筚路蓝缕, 以启山林一一开始他 们最初的生活, 直到 20 世纪初成为在苏门答腊最有影响力的和慷慨的领导人。 除了被誉为棉兰市的主要商人和知名人物外, 张氏兄弟还具有很高的并且不区分 种族、宗教和社会地位的社会敏感和社会关怀。正因如此, 张氏兄弟的名字与棉 兰市的历史是不可分开的。

\section{1.3 张阿辉}

Agnes Davonar（2016 年), 在她的书”张阿辉大女儿的生活故事一一棉兰 最富有的人”里, 作者讲述了作为一个大型财团企业家的女儿且生活富足, 她生 活之中的悲喜和曲折经历, 以及她的的父亲曾经作为一个贫穷的年轻人在中国大 陆多年的艰苦斗争的故事。她的父亲凭借他的辛勤工作和坚忍不拔, 成功地成为 了苏门答腊土地上一个伟大的商人一一仅凭 10 分钱的资本和钢铁般的决心与意 志。尽管作为富豪, 并被任命为棉兰市的华人社区的领袖, 但张阿辉却是一个慈 爱和慷慨的人物。直至今天, 他仍然被整个苏门答腊人民铭记, 甚至到马来亚都 传颂着他的故事一一因为他的美德和善良, 从不区分部落, 种族和宗教。

\section{三 张氏兄弟在日里地区的贡献}

\section{1 运营}

张氏兄弟所采用的道路从种植园用品开始, 转向橡胶种植和农业收入等 相关业务, 然后再进入房地产, 酒店, 银行, 种植园, 棕榈油和糖厂业务。促 进他们扩展到大量的商业活动, 是他们与苏门答腊地区以及其他地区的殖民地 企业家, 本土商人, 中国商人之间的关系。特殊的商业企业家被安置在 Chong Lee 公司。由于政府提供的设施和他们的商业活动, 张氏兄弟在房地产, 酒店, 银 行，种植园，棕㭣油和糖厂有巨大的收益。 


\section{2 市场与医院}

作为一名中国军官, 张兄弟们事先知道了棉兰的规划, 购买了周围的土 地并建造了一排排中式和欧式风格的房屋。1886 年，他们建立了肉类市 场; 一年之后，1887 年，建立了一个鱼市场；1906 年建立了一个蔬年建立了一个 蔬菜市场。1890 年，市场利润转向了建立 Tjie On D jie Jan 基金会，从此基金 会向日里地区的中华民族 T jie On D jie Jan 医院出资。这家医院免费收治病 人。

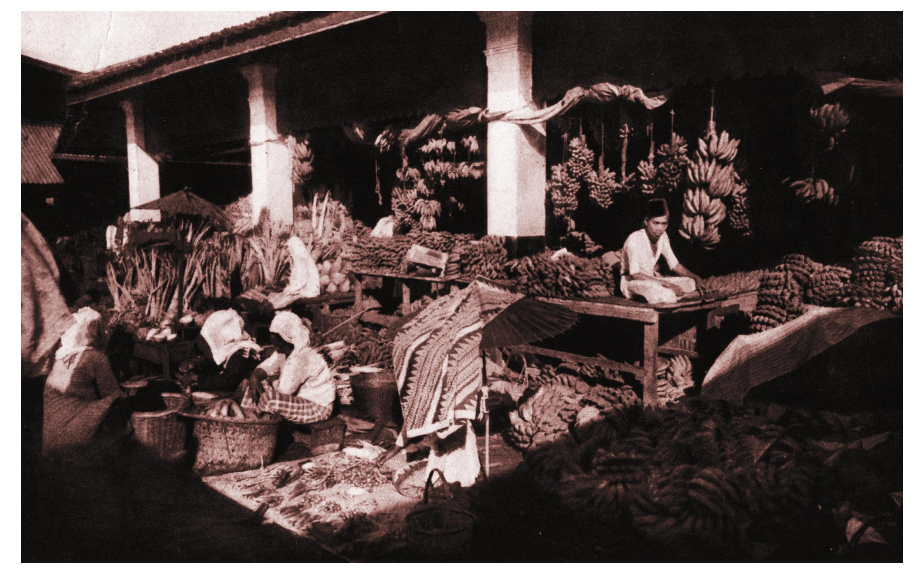

图 3 棉兰市场 (Dok. Arsip Museum Tjong A Fie Mansion)

\section{3 火车}

中国南部的汕头火车是一个较大的合资企业。在中国现代化进程中, 张氏兄弟与张肇敲一起, 在汕头和潮州之间建造了一条铁路。1906 年, 铁路开 始运营, 第一条铁路由中国以外的华人建造和资助。张榕轩成为董事长。1909 年, 张榕轩的长子, 张步青担任董事。这列火车最终被中国和日本公司 所实现。 张榕轩在中国进行重大投资的计划, 特别是在潮州列车上的计划, 源于 志向和民族主义以及张肇焳加入该项目的请求。张榕轩的财富的增加也为自 己和家人赢得了权力和声望。

\section{4 日里银行}

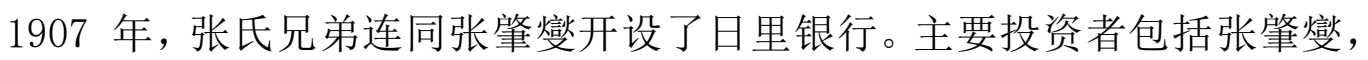
F200, 000, 张榕轩 F150, 000, 张亚辉 F100, 000, Khoe Tiong T jaw (Khoo Cheow Teong), 丹线峇来商人, F100,000 和谢春生, 前 Koetaradja（班达 亚齐）的 
中国中尉, 然后是槟城商人, F100, 000。管理委员是张肇容和张榕 轩及总监是 张亚辉, Khoe Tiong Tjauw和谢春生。

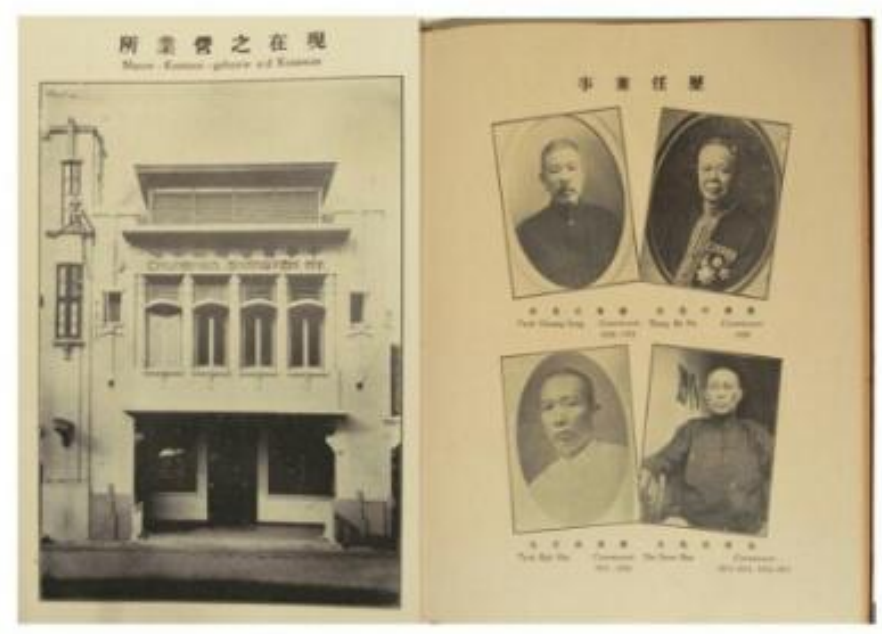

图 4 日里银行 (Dok. Arsip Museum Tjong A Fie Mansion)

\section{5 美德桥梁}

在张榕轩离世后, 他的妻子命令他的儿子在棉兰市建造三座桥梁。这座 桥旨在纪念张榕轩作为日里地区有影响力的人物之一。这三座桥梁中只剩下一 座桥梁, 直到现在仍然可以见证并被日里社会称为美德桥梁。美德桥在 张榕轩 离世五年后建成, 就在 1916 年。它的存在继续坚定, 直到 20 世纪 70 年代, 棉 兰市政府拓宽了道路。因为起初新棉兰区是荷兰种植园, 称为Civev种植园, 现 在这片土地被用作剑桥大楼。由于坚固的桥梁支柱所 以桥梁也不会折叠。然后, 由苏门答腊文物局协助张榕轩后裔把美德桥梁作 为遗产并在 2003 年获得了教科 文组织的奖赏。

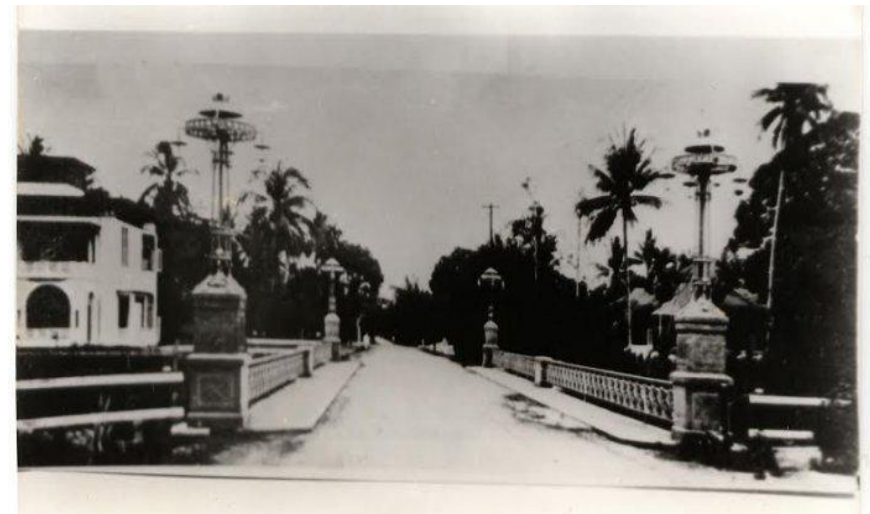

图 5 善行桥 (Dok. Arsip Museum Tjong A Fie Mansion) 


\section{四 结语}

角色参与对一个地方或区域的构建和形成至关重要。通过这些关键角色的参 与, 社会公众将会意识到并开始了解那些为社会环境做出贡献的人。本文重点介 绍了张氏兄弟在日里地区的角色参与。在殖民时期, 张榕轩和张阿辉是祖籍中国 并在日里地区成为精英阶层参与者的主要人物。他们恰恰在正确的时间, 身处于 非常具有战略性的日里地区。基于围绕各种张氏兄弟生活的社会方面作为一个出 发点, 并从中获得了关于张氏兄弟存在于日里地区的角色之探讨一一这种角色的 参与即是: 在 20 世纪初, 日里苏丹国给予其信任, 使之成为一个市议会和文化 委员会在日里地区的成员; 任命张氏兄弟为日里地区的主要华人社区领袖; 在马 德拉斯村（棉兰市扎伊努尔阿里芬路）建造福利桥, 建造这座桥是张氏兄弟为便 利日里地区之间的运输而首倡的一项举措; 建造拉玛清真寺, 也称为 “埲空胡同 清真寺”, 是本地百姓请求建造的礼拜场所; 这一要求随后得到张阿辉的批准和 全额资助。在社会上，清真寺的建设对日里地区人民的生活产生了深远的影响; 连接棉兰和贝拉万市的火车轨道运输设施是张氏兄弟考虑的结果, 使得地区之间 （棉兰一贝拉万市）的通行更加便利。

张氏兄弟对日里地区的社会经济领域发展的各种参与表明, 他在日里地区（棉 兰市) 开发中发挥了重要作用。唤起公众对张氏兄弟的记忆, 不仅是一种必要的 公开需要, 也是棉兰市政府在促进张阿辉府邸和张榕轩展览馆的历史旅游中的重 要内容。通过这种方式, 人们将回忆并感受张氏兄弟在开发和建设日里地区（棉 兰市）各个方面的贡献和作用是多么伟大与崇高。 


\section{参考文献}

[1] Agustono, Budi. (2012). Tjong Yong Hian: Sang Pembangun Kota Medan. Disampaikan pada Seminar Mengenang 100 Tahun T jong Yong Hian, Medan, Sumatera Utara.

[2] Buiskool, D. A. (2009). 6 The Chinese Commercial Elite of Medan, 1890-1942: The Penang Connection. Journal of the Malaysian Branch of the Royal Asiatic Society, 82(2), 113.

[3] Chandra, Rebecca. 2011. Warisan Seorang Pemimpin Sejati: Tjong Yong Hian. Medan: Budihardjo Chandra and Family.

[4] Chang, Q. 1981. Memories of a Nonya, Singapore: Markono Print Media Pte Ltd.

[5] Pin, P. (2017). Family Business Generation in Medan, Indonesia with Efforts to Adapt to the Changes in Government System. International Journal of Management Science and Business Administration, 3(6), 58-59.

[6] Pin, P., Subhilhar, S., Kusmanto, H. , \& Purba, A. (2018). Tjong Yong Hian And the Development of The City of Medan, The Existence of Chinese The Economy Field in Indonesia.

[7] Rudiansyah, G. G., \& Nugrahanto, W. Unsur Akulturasi Budaya pada Rumah Tjong A Fie di Kota Medan. Pantun Jurnal Ilmiah Seni Budaya ISBI Bandung. 2(1) : 44-53.

[8] Rudiansyah, G. G., \& Nugrahanto, W. (2016). FUNGSI PUAK POI PADA UPACARA PAISIN DALAM BUDAYA MASYARAKAT TIONGHOA DI KOTA MEDAN. Jurnal Kajian Seni, 3(01), 31-42.

[9] Tanjung, R., Rudiansyah, R., \& Chen, J. (2019). LAMA GANG BENGKOK MOSQUE AS A MULTIETHNIC SYMBOL IN THE CITY OF MEDAN. JADECS, 4(2), 95-103. 
DATA PENULIS（作者简介）

Name ：Rudiansyah（卢耀轩）

Country : Indonesia

University : University of Sumatera Utara

Hp/WhatsApp : +62 821-6477-7811

Email : rudiansyah@usu. ac.id

DATA PENULIS（作者简介）

Name : Arthur S. Nalan

Country : Indonesia

University : Institut Seni Budaya Indonesia

Hp/WhatsApp : +62 812-2378-061

Email : arthur@isbi.ac.id

DATA PENULIS（作者简介）

Name

: Yang Jing (杨景)

Country : China

University : Shanghai International Studies University

Telp. : : +86 1590-1600-952

Emai1 : 0193701183@shisu. edu.cn 